\title{
Etno-história e história indígena: questões sobre conceitos, métodos e relevância da pesquisa
}

\section{Ethnohistory and indigenous history: questions about concepts, methods and relevance of research}

Thiago Leandro Vieira CAVALCANTE*

Resumo: A partir de década de 1990 a pesquisa em história indígena tem crescido tanto numérica, quanto qualitativamente na academia brasileira. Nesse quadro, os conceitos de "etno-história" e "história indígena” têm sido utilizados, muitas vezes, de maneira imprecisa. Este artigo aborda a história do conceito de "etno-história” e seus principais desdobramentos. Além disso, discute o caráter interdisciplinar da pesquisa em história indígena e sua relevância social. Também são abordadas questões sobre a formação de recursos humanos para ensino e pesquisa em história indígena, ensino de história indígena em contexto de educação básica e a ética profissional do pesquisador em história indígena.

Palavras-chave: Etno-história. História indígena. Interdisciplinaridade.

\begin{abstract}
Since the 1990s, research into indigenous history has grown both quantitatively and qualitatively in Brazilian academia. Nevertheless the concepts of ethnohistory and indigenous history have been frequently used imprecisely. This article discusses the concept of ethnohistory and its development. Also, it discusses the interdisciplinary character of research into indigenous history and its social relevance. Questions are also raised about the training of human resources for teaching, the research into indigenous history, the teaching of it in the context of basic education and the professional ethics of the researcher.
\end{abstract}

Keywords: Ethnohistory. Indigenous History. Interdisciplinary.

\footnotetext{
* Mestre em História pela UFGD, Doutorando pelo Programa de Pós-graduação em História - Faculdade de Ciências e Letras de Assis - UNESP - Universidade Estadual Paulista, Campus de Assis, Brasil. Bolsista do CNPq. E-mail: thiago_cavalcante@hotmail.com
} 
Desde o início do século XX, a história indígena, orientada pela metodologia etno-histórica, tem sido tema de numerosos trabalhos na América do Norte, na Austrália e na região do Pacífico (TRIGGER, 1982, p. 30). A partir da década de 1990, os estudos sobre história indígena no Brasil vivenciaram grande efervescência que pode ser constatada pelo significativo número de trabalhos publicados e também pelo crescente número de dissertações e teses que abordaram a questão em diferentes programas de pós-graduação do país. Há também grupos, linhas, laboratórios e núcleos de pesquisa em diferentes instituições universitárias brasileiras, como, por exemplo, na Universidade Estadual de Maringá, na Universidade Federal da Grande Dourados, na Universidade Federal de Santa Catarina e na Universidade de São Paulo, que trazem em seus nomes os termos "história indígena” ou “etno-história”.

Muitos trabalhos são identificados como filiados à "história indígena”, outros à “etnohistória”. Esses dois conceitos são utilizados para designar diversas pesquisas que, em sua maioria, envolvem questões indígenas com abordagens históricas. Apesar disso, nem sempre tais conceitos são apresentados com clareza. Considerando que podem se desdobrar em diversas semânticas, especialmente o conceito de “etno-história”, alguns de seus usos podem conduzir a imbróglios. Ao menos dois autores (GALDAMES, 1988; EREMITES DE OLIVEIRA, 2003) já se dedicaram a discutir as diferenças e aproximações entre "história indígena” e “etno-história”. Dialogando com eles e também com outros que já trataram dessa questão, pretende-se com esse trabalho contribuir para com essa discussão.

Por um lado, pretende-se oferecer uma síntese da discussão, destacando, sobretudo as diversas definições do conceito de “etno-história” e por outro problematizar algumas questões a partir da própria experiência em pesquisas no campo da história indígena com a utilização da metodologia etno-histórica. Como tentativa de síntese, devido ao grande número de autores que já trataram do tema, este trabalho não pode ser completo no sentido de incluir a posição de todos aqueles que já se manifestaram sobre a questão. Apesar disso, com relação às diferentes acepções conceituais para o termo “etno-história”, o texto procura abarcar a integralidade dos posicionamentos mais relevantes.

Inicialmente apresentar-se-á uma introdução sobre o conceito de “etno-história” e, em seguida, serão abordadas as diversas acepções do conceito, ou seja: a) como disciplina acadêmica independente; b) como compreensão e/ou representação própria dos povos indígenas acerca de sua história e do tempo; c) como uma etnociência; e d) como um método interdisciplinar. Por fim, tratar-se-á da história indígena e de alguns aspectos de seu desenvolvimento mais recente no Brasil. 


\section{Etno-História}

O primeiro registro de uso do termo etno-história data de 1909, quando Clark Wissler o empregou para se referir à utilização de documentos escritos e dados arqueológicos para a reconstrução da história de culturas indígenas (EREMITES DE OLIVEIRA, 2003; ROJAS, 2008). Inicialmente a etno-história foi ligada apenas ao estudo de sociedades culturalmente não-ocidentais e ágrafas. Pretendia-se que fosse a história de povos ágrafos escrita a partir de fontes produzidas por outros povos, predominantemente, portanto, em situação colonial. Segundo essa definição, a etnohistória estava próxima de ser uma espécie de "história dos povos sem história”. No entanto, brevemente a definição teve seus limites ampliados, chegando-se próximo de um consenso em torno da ideia de que a etno-história é um método interdisciplinar de pesquisa (ROJAS, 2008).

O caráter ágrafo das culturas não-ocidentais, chave dessa primeira concepção, foi questionado por Rojas. O autor destaca que é certo que a maioria das diversas culturas nativas da América é essencialmente oral, mas não se pode desprezar o fato de que logo no princípio da dominação colonial muitos indígenas foram alfabetizados, tanto nas línguas europeias quanto em algumas línguas indígenas que foram submetidas a sistemas gráficos europeus. Esse processo de redução à escrita das línguas indígenas e de alfabetização de indígenas em línguas ocidentais continua até a atualidade e tem uma série de implicações, incluindo aí a produção de textos diversos e o registro escrito da memória dos grupos. Isso altera significativamente o conjunto de registros que podem ser tomados como fontes para a escrita da história dessas populações.

Rojas destaca, também, que para além dos sistemas ocidentais inseridos na América colonial, há casos de sistemas de escrita criados pelos próprios indígenas, como, por exemplo, o Cherokee Sequoia da América do Norte, que foi criado no princípio do século XIX. Lembra, ainda, que na Mesoamérica, antes da chegada dos europeus, a escrita já era uma realidade que não podia ser ignorada, pois alguns desses povos já escreviam em diferentes suportes como a cerâmica, a pedra, a madeira, os ossos e o papel. A frequente dificuldade encontrada para a decifração desses escritos não converte os mesoamericanos em povos ágrafos (ROJAS, 2008).

De acordo com a American Society for Ethnohistory, o termo etno-história em sua premissa teórica básica atual, ou seja, associado a um método, foi utilizado pela primeira vez em 1930 por Fritz Röck no Viennese Study Group for African Culture History. Tal grupo emergiu como uma reação ao predomínio da Vienna School of Culture Historical Ethnology. Sua intenção era criar modelos que possibilitassem que a história fosse desenhada a partir de dados etnográficos coletados 
na África. O movimento não conseguiu, no entanto, transpor as suas proposições teóricas para a prática, fundindo-se, em seguida, com a chamada etnografia histórica (ASE, 2010).

Segundo Trigger (1982), A. G. Bailey, um historiador graduado pela Universidade de Toronto, publicou em 1937 aquele que provavelmente foi o primeiro grande estudo de etno-história norte-americana, intitulado "El conflicto entre las culturas europea y algonkina oriental, 15041700”. Apesar da existência desse trabalho, foi apenas a partir da década de 1950 que e a etnohistória efetivamente se desenvolveu na América do Norte tanto como disciplina quanto como método (ASE, 2010). Após vários debates, que serão, em parte, retomados a seguir, a definição de etno-história que se consolidou na América do Norte foi aquela que identifica o conceito como um método interdisciplinar, isso porque o uso do termo para designar uma disciplina foi julgado inapropriado pela maioria dos especialistas.

Um fato histórico contemporâneo é apontado como o grande impulsionador do desenvolvimento dos estudos etno-históricos sobre as populações indígenas da América do Norte. Trata-se da proclamação, pelo Congresso dos Estados Unidos da Indian Claim Act ${ }^{1}$, que permitia que os indígenas reivindicassem compensações pelas terras das quais haviam sido retirados sem a existência de qualquer tratado (ROJAS, 2008; CARMACK, 1979; ASE, 2010).

Essas reivindicações geraram grande demanda de pesquisas etno-históricas e muitos pesquisadores, principalmente antropólogos, se envolveram nesses trabalhos. Inicialmente foram produzidos laudos que demonstravam que, em alguns casos, existiam tratados cujos termos precisavam ser analisados, visto que possivelmente não haviam sido cumpridos e identificavam também as antigas localizações das terras exigidas, enfim, produziam, por meio dos necessários estudos diacrônicos, pesquisas que permitiam fundamentar as reivindicações indígenas bem como embasar as decisões do poder judiciário (ROJAS, 2008).

Situação similar a essa vem sendo vivida no Brasil, a partir da promulgação da Constituição Federal de 1988, a qual garantiu vários direitos aos povos indígenas, especialmente o direito aos seus territórios tradicionais, gerando assim grande demanda e valorização das pesquisas diacrônicas sobre os povos indígenas no país. Isso conduz, inevitavelmente, a reflexões sobre a relevância social das pesquisas, bem como a uma necessária ética que deve estar sempre presente nas preocupações do pesquisador, temas aos quais se retornará mais adiante.

Em 1950 os laudos antropológicos e históricos produzidos nos Estados Unidos foram reunidos pela primeira vez na Ohio Valley Historic Indian Conference que posteriormente ficou conhecida como American Indian Ethnohistoric Conference, fundada em 1954, afiliada à Indiana University em Bloomington. Em 1966 a Conferência mudou seu nome para American Society for Ethnohistory, que publica desde 1954 o periódico Ethnohistory ${ }^{2}$, ainda pouco conhecido no Brasil. 
A mudança de denominação marcou a abertura para estudos sobre povos indígenas de outras partes do mundo já que, até então, as pesquisas se concentravam especialmente nos povos norteamericanos. Essa sociedade é ainda responsável pelo The Ohio Valley-Great Lakes Ethnohistoriry Archive $^{3}$, formado entre 1953 e 1966, que continua sendo considerado, pela American Society for Ethnohistory, como a mais importante coleção sobre a temática.

Os primeiros passos da etno-história foram dados por antropólogos, mas com o passar do tempo vários historiadores e também outros pesquisadores, como, por exemplo, geógrafos e arqueólogos, passaram a se interessar pela problemática. Assim a etno-história caminhou para se consolidar como um método que congrega, principalmente, aportes da antropologia e da história, mas também e com grande importância de outras disciplinas, tais como a arqueologia e a linguística, por exemplo (EREMITES DE OLIVEIRA, 2003; ROJAS, 2008; TRIGGER, 1982).

\section{Etno-História como disciplina acadêmica independente}

Num primeiro momento pensou-se ser possível definir a etno-história como uma disciplina independente, mas logo se chegou à conclusão de que isso não era uma boa alternativa. Sobre a problemática da definição acerca do que é etno-história, o ensaio de Bruce Trigger (1982), já no início dos anos 1980, dava esse assunto quase que por superado, ao menos nos Estados Unidos. No Brasil, conforme Jorge Eremites de Oliveira (2003) ainda há certa confusão e, de fato, mesmo já quase uma década depois da publicação do artigo deste autor, ainda é comum encontrar alguma confusão e, às vezes, ensaio de querela em torno dos usos do conceito.

Segundo Trigger, nos primeiros números de Ethnohistory muito se discutiu sobre esse tema. A partir da análise de Bryde, Trigger informa que as discussões procuravam responder se a etnohistória era uma disciplina independente, ou uma sub-disciplina da antropologia ou da história, ou uma técnica especial de análise dos dados ou ainda uma maneira convincente de fornecer dados para outras disciplinas. Discutia-se também se a etno-história estava mais ligada à antropologia ou à história, ou se era simplesmente uma espécie de “terra de ninguém”. Discutia-se se comportava a descrição etnográfica das culturas históricas e a chamada etnografia histórica e ainda se essas duas em contraposição ao estudo das mudanças culturais a partir dos primeiros contatos com os europeus eram ramos diferentes de etno-história. Segundo o autor, aparentemente não houve um acordo sobre essas questões.

Houve, todavia, um acordo tácito, que considerou a etno-história como uma metodologia que se utiliza principalmente de evidências documentais e tradições orais para estudar as transformações nas culturas das sociedades sem escrita da América, sobretudo para o período 
posterior ao processo de conquista europeia da América (TRIGGER, 1982). A inclusão das metodologias arqueológicas possibilita ainda pensar em uma abordagem mais holística incluindo a histórica pré-colonial indígena no escopo de preocupações numa perspectiva de longa duração (EREMITES DE OLIVEIRA, 2001; EREMITES DE OLIVEIRA, 2003).

Apesar do exposto, não se deve pensar que a refutação da etno-história como disciplina independente tenha acontecido pela simples falta de acordo entre seus adeptos oriundos de disciplinas diferentes. Se de fato há discordâncias entre eles, também é preciso destacar as questões ideológicas e epistemológicas envolvidas no assunto que sustentam a ideia de que a etno-história não pode ser tomada como uma disciplina.

Já é muito conhecida a clássica e aparentemente superada dicotomia entre antropologia e história que, no século XIX se definiam a partir de seus objetos de estudo. A primeira se dedicava ao estudo das culturas nativas não-ocidentais consideradas inferiores e estáticas, culturas ahistóricas, portanto. Já a história devia se preocupar com as culturas de origem europeia ávidas pela mudança e especialmente letradas, o que permitia produzir e deixar muitos documentos escritos sobre o próprio passado. Essa distinção entre as duas disciplinas estava, sem dúvida, ligada aos ideais expansionistas e racistas presentes nas ciências sociais (incluindo a história) durante o século XIX e que fundamentaram discursos sobre a colonização da América, além de, em parte, terem sustentado os ataques neocoloniais daquele século, especialmente em direção à África.

No caso do Brasil, a famosa frase de Francisco Adolfo Varnhagen, escrita em sua "História Geral do Brasil” de 1854, segundo a qual para os índios “[...] não há história, há apenas etnografia” (VARNHAGEN apud MONTEIRO, 1995, p. 221) ilustra bem esse pensamento. Segundo Manuela Carneiro da Cunha, no Brasil, até a década de 1970, os indígenas não tinham nem passado e nem futuro, seu fim era visto como certo e estava próximo. A ausência de seu passado era corroborada por historiadores e antropólogos. Os primeiros hesitavam em se livrar do fetiche pelas fontes escritas, e escritas pelos próprios atores históricos, por isso não davam atenção à história indígena, que muitas vezes, só pode ser feita com o uso de fontes de terceiros, fontes materiais e/ou com o uso de tradições orais, sobre as quais pesavam muitas desconfianças. Já no caso dos antropólogos sua abstenção é atribuída a algumas de suas filiações teóricas, como, por exemplo, o evolucionismo, para o qual os indígenas não tinham passado, pois, de certa forma, eram o próprio passado, o ponto inicial da humanidade. A mesma abstenção foi praticada pelos funcionalistas e estruturalistas que, por razões diversas, privilegiaram a análise sincrônica da sociedade (CUNHA, 2009).

Apesar desse quadro histórico, hoje, ainda que seja claro que as diversas culturas possuem diferentes historicidades (SAHLINS, 2003), é quase inquestionável a ideia de que os povos indígenas têm história, visto que há dinamismo cultural e que ele é facilmente observável. Nesse 
sentido o uso do conceito de etno-história para designar uma disciplina que se dedica a estudar a história dos povos indígenas ou “nativos”, como os chama Trigger, é visto por este autor como uma atitude etnocêntrica. A existência de uma disciplina etno-histórica separada da história, indicaria que a história dos povos indígenas é cumulativamente diferente da dos povos ocidentais letrados. Por isso, o autor defende que se a intenção for se livrar dos prejuízos causados pela dicotomia antropologia e história do século XIX, deve-se abandonar o uso do termo etno-história para designar uma disciplina, passando-se a falar apenas em história nativa ou, num contexto mais atual história indígena ou ainda mais especificamente da história de cada povo (TRIGGER, 1982).

Serge Gruzinski, em entrevista concedida a Maria Celestino de Almeida (2007), destacou que no México durante muito tempo a etno-história cuidava dos índios, enquanto a história se dedicava aos “brancos”. Segundo ele, a melhor opção é estudar a história dos índios. Destaca ainda outro problema, pois se praticamente já não há mais a imposição da distinção entre as disciplinas, a preocupação de alguns pesquisadores em privilegiar a voz dos indígenas, focando apenas no protagonismo indígena, tem levado à utilização maciça de fontes escritas por indígenas. Na opinião do autor, essa abordagem radical, que despreza a visão colonial, também contribui para a manutenção da dicotomia entre história e etno-história (GRUZINSKI, 2007).

Rojas defende uma posição ainda mais radical, segundo ele, mesmo o termo história indígena é etnocêntrico, pois o erro estaria em querer estudar separadamente a história de sociedades que estão mescladas no contexto colonial (ROJAS, 2008). Essa posição encontra ressonância entre outros importantes pesquisadores e será novamente abordada na última parte deste trabalho, mas é preciso ressalvar que Rojas, historiador de formação, indica que as preocupações da etno-história se voltam principalmente para o período colonial; portanto, não está alinhado a um pensamento mais holístico que não aceita o rompimento entre uma pré-história indígena e uma história indígena iniciada a partir do contato colonial.

\section{Etno-História como compreensão e/ou representação própria dos povos indígenas acerca de}

\section{sua história e do tempo}

Há, ainda, uma visão que define a etno-história como a compreensão ou a representação que os povos indígenas fazem sobre a sua própria história ou sobre as suas categorias de tempo, a rigor sobre suas historicidades. Esta é a visão defendida por dois nomes importantes da antropologia brasileira, Manuela Carneiro da Cunha e Eduardo Viveiros de Castro que assim se expressaram: “[...] procurava-se perceber, naquilo que propriamente se poderia chamar de etno-história, a 
significação e o lugar que diferentes povos atribuíam à temporalidade” (CUNHA, 2009, p. 127). A etno-história é “[...] entendida no seu sentido próprio de auto-concepções da história forjadas pelas diferentes sociedades indígenas[...]” (CASTRO \& CUNHA, 1993, p.12).

$\mathrm{Na}$ mesma linha de pensamento, ainda que também proponha uma metodologia etnohistórica (MELIÀ, 1997, p.96), segue a proposição de Bartomeu Melià, que se refere especificamente ao caso dos Guarani. Para ele, a etno-história, não é uma história que simplesmente trata dos Guarani, “[...] No es el Guaraní en la historia, ni el Guaraní de la historia, sino la historia del Guaraní, en cuanto que es éste quien sabe sus tiempos e los sinte [...]”. Segundo ele, para se chegar a isso é preciso descobrir os esquemas culturais e as relações de valores próprios dos Guarani (Melià, 1997, p. 35).

Esta é a definição de etno-história mais literal do ponto de vista etimológico. Não é, no entanto, a única aceitável, por isso a constatação de múltiplos significados para o mesmo conceito reafirma a importância de o pesquisador apresentar, ao menos, uma pequena nota indicando que sentido está atribuindo ao conceito quando utilizado. Existe aqui, também, um importante campo de estudos, sobre o qual alguns trabalhos já foram publicados (CASTRO \& CUNHA, 1993 e REVISTA DE ANTROPOLOGIA n. 30/31/32, 1987/1988/1989, por exemplo), mas que ainda tem muito por fazer, visto que a aceitação teórica de que as diferentes culturas possuem diferentes historicidades (SAHLINS, 2003) não basta para seu conhecimento efetivo.

Ressalta-se, no entanto, que essa abordagem não pode desconsiderar o ambiente colonial no qual as representações indígenas estão sendo produzidas. A desconsideração desse contexto leva inevitavelmente à construção de representações essencialistas dos grupos indígenas e de suas culturas, tais representações são inaceitáveis no estágio atual das pesquisas.

Esta perspectiva de etno-história enfoca de maneira privilegiada a abordagem "êmica”, ou seja, a representação que os indígenas fazem de si mesmo. Esta visão se opõe à chamada abordagem “ética”, que se refere àquelas representações feitas a partir de chaves interpretativas externas. Eremites de Oliveira destaca, no entanto, que o uso da abordagem êmica não é tão simples quanto pode parecer, pois

[...] a aparente dicotomia entre o ético (nossa representação sobre o "outro") e "êmico" (a representação dos indígenas sobre si), remete a uma longa e antiga discussão aparentemente longe de um entendimento consensual: história/eventos/diacronia versus estrutura/mitos/sincronia. Isto porque, sem recorrer neste momento a um alhures no campo da chamada antropologia histórica, a visão que os próprios nativos constroem sobre sua trajetória é, em muitos casos, impregnada por complexas representações simbólicas não facilmente decodificáveis e passíveis de serem ordenadas em termos temporais (Eremites de Oliveira, 2003, p. 40). 
Etno-história e história indígena: questões sobre conceitos, métodos e relevância da pesquisa

Esta observação demonstra que propor uma abordagem êmica não significa apenas “dar voz” aos povos estudados, mas, em muitos casos, subverter a maneira linear com a qual se está acostumado a pensar a história, a partir da historicidade ocidental. Eremites de Oliveira destaca, ainda, que a construção de uma história indígena pode ser norteada para mais ou para menos em torno das perspectivas ética ou êmica. O maior ou menor uso da tradição oral como fonte interfere significativamente nessa balança.

Robert Carmack inclui essa acepção do termo etno-história entre as três matérias, que, segundo ele, são as mais estudadas pelos etno-historiadores, que são a história específica, a etnografia histórica e a história folk (CARMACK, 1979). A acepção ora discutida é enquadrada por ele na chamada história folk, que, para ele, é o estudo da visão que uma sociedade tem sobre o seu próprio passado. Essa visão é incluída como parte integral da cultura e por isso se constitui num aspecto especial da reconstrução etnográfica. Assim, o estudo da história folk pode ser tomado como o significado literal do termo etno-história, que seria “[...] la historia dos grupos étnicos ou culturas...”. Com esse sentido o conceito de etno-história assume semântica similar a outros como etnomedicina, etnobotânica, etnomusicologia e etc. (CARMACK, 1979, p. 31).

Um dos focos de estudo destacados pelo autor está a preocupação com a atitude cultural que um povo tem diante da passagem do tempo. Outro ponto que também pode ser explorado são as mitologias que podem ser abordadas a partir de uma perspectiva ultrapassa a narrativa e se preocupa, por exemplo, com as implicações históricas do mito, suas relações com os rituais, sua fundamentação em estados psicológicos, suas funções sociológicas e seus usos na reconstrução da história cultural (CARMACK, 1979).

Essa abordagem ajuda também no trabalho de crítica necessário a qualquer pesquisador que utilize fontes escritas ou orais originárias de povos indígenas. Citando Boston, Carmack destaca que as tradições orais de cada povo têm suas próprias perspectivas históricas e a primeira tarefa do historiador é compreender essas perspectivas antes de tentar inseri-las na escala linear ocidental (CARMACK, 1979). Essa observação certamente ajuda, sobremaneira, no trabalho de crítica das fontes e pode diminuir os problemas oriundos da leitura de fontes indígenas a partir de chaves hermenêuticas não-indígenas.

Essa acepção de etno-história busca compreender a história indígena a partir das chaves culturais próprias dos grupos estudados, analisando como os atores sociais percebem a sua própria história, ou seja, pretende apresentar uma visão êmica. No entanto, este trabalho é, em geral, feito por um pesquisador externo ao grupo tomado como objeto de estudo, esta é a principal diferença em relação à acepção do conceito de etno-história da qual se tratará a seguir. 


\section{Etno-História como uma etnociência}

Nos últimos anos, ainda que seja tímida, tem crescido a participação de indígenas em cursos superiores, participação essa que não se limita aos cursos de graduação, ocorrendo também em cursos de pós-graduação stricto sensu. Tal participação, tem se demonstrado muito positiva, pois os indígenas formados nas mais diversas áreas tendem a se tornar interlocutores privilegiados entre os grupos indígenas e a sociedade envolvente, especialmente com o Estado brasileiro, tornando-se potenciais defensores dos direitos coletivos de seus grupos. É claro que esse quadro apresenta, também uma série de implicações sociológicas que não podem ser aqui discutidas.

Muitos desses acadêmicos indígenas têm se dedicado às áreas da história e da antropologia, inserindo, muitas vezes, suas pesquisas no campo que está sendo discutido neste artigo. Paralelamente a esse fenômeno social, tem surgido, ainda que não de maneira escrita e sistematizada, uma nova acepção para o conceito de etno-história como a história indígena escrita por indígenas, ou seja, uma etnociência, muitas vezes confundida com a concepção apresentada no item anterior.

Este é um fenômeno ainda muito recente e conclusões acerca dele podem ser precipitadas, pois ainda não é possível saber o exato alcance e a repercussão que essas pesquisas terão. Não há dúvida, no entanto, de que um pesquisador indígena que se dedica à história de sua própria etnia está em condições muito mais favoráveis do que a maioria dos outros pesquisadores para analisar a história desse povo, sobretudo a partir de uma perspectiva êmica. Nesse sentido, tudo indica que logo se terá acesso a trabalhos com uma perspectiva renovada e rica, especialmente para os povos indígenas.

Apesar disso, uma importante questão não pode ser esquecida, trata-se do processo autoral que envolve a produção de qualquer trabalho acadêmico nos moldes ocidentais, sistema no qual, mesmo nas ditas propostas interculturais, os acadêmicos indígenas estão se inserindo. Desde que os historiadores sepultaram os pressupostos da escola histórica ou metódica, é praticamente unânime entre as várias correntes da historiografia a ideia de que o pesquisador exerce papel ativo e, portanto, subjetivo na produção do conhecimento histórico. Diante disso, não se deve cair na tentação de considerar uma história indígena produzida por indígena como "a verdade” ou uma história definitiva, nem tampouco como uma história automaticamente melhor do que as outras.

Não se pode esquecer que o pesquisador indígena é também um indivíduo (ainda que o peso da individualidade possa ser discutido em relação ao social em alguns grupos indígenas) que exerce diversos papéis sociais e pode ocupar diferentes posições de prestígio no sistema social ao qual está inserido, podendo inclusive estar envolvido em conflitos de interesses internos e em alguns casos 
ter aderido a igrejas cristãs de diversas confissões, etc.. Além disso, não se deve imaginar que todos os indígenas dominam a integralidade de "sua cultura”, um xamã, por exemplo, certamente sabe mais sobre os mitos de "sua cultura” do que um indivíduo comum, etc.. Há ainda que se considerar as interferências que os orientadores e o contexto institucional acadêmico podem exercer na produção do conhecimento. Enfim, todas as variáveis observadas na leitura crítica de um trabalho, diga-se “comum”, devem também ser consideradas na leitura de autores indígenas que escrevem sobre história indígena ou sobre a questão indígena de maneira mais ampla.

Essas observações não desmerecem, de forma alguma, a produção de pesquisadores indígenas, muito pelo contrário, observa-se que essas contribuições representam um inestimável avanço no sentido do diálogo intercultural e do conhecimento histórico efetivamente êmico. No entanto, as representações históricas individuais não podem ser automaticamente convertidas em coletivas.

\section{Etno-História como um método interdisciplinar}

A visão que qualifica a etno-história como um método interdisciplinar que conjuga dados e métodos da antropologia, da história e da arqueologia é a que encontra maior ressonância entre os autores aqui referenciados e é também a perspectiva que está sendo aplicada às atividades de pesquisa até aqui desenvolvidas. Nesse sentido, caminham as posições de Robert Carmack (1979), Bruce Trigger (1982), de Jorge Eremites de Oliveira (2003) e de José Luis de Rojas (2008).

De acordo com essa acepção, a etno-história, como método interdisciplinar, é o melhor caminho para se compreender os povos de culturas não-ocidentais a partir de uma perspectiva histórica. Nesse sentido, é dada muita importância às tradições orais e às fontes arqueológicas, que podem oferecer dados bastante valiosos sobre essas culturas, as quais, em sua maioria advêm de tradições ágrafas. A linguística também tem se demonstrado uma valiosa aliada nesse campo de pesquisa, os estudos de linguística histórica são capazes de apresentar diversos aspectos que dificilmente seriam acessados por outras vias (CHAMORRO, 2009).

A documentação escrita, seja ela produzida por indígenas seja por não-indígenas, tem também grande destaque. Nesse sentido, é fundamental que as técnicas de crítica documental sejam aplicadas com bastante destreza pelos pesquisadores. Bartomeu Melià aponta que a documentação colonial foi produzida sobre a perspectiva da "redução" do indígena à vida política e humana, então, o método etno-histórico indicado para a análise das fontes coloniais consiste precisamente em desideologizar as fontes (MELIÀ, 1997). A proposta é uma espécie de análise discursiva da qual se 
pode retirar não apenas as representações acerca dos indígenas, mas também dados para uma possível etnografia histórica.

Melià apresenta sua proposta pensando especialmente nos grupos por ele estudados. Assim, apresenta outro recurso para a semantização dos elementos fornecidos pelas fontes coloniais, especialmente pela documentação jesuítica. Tal recurso presume a análise da documentação a partir da cultura dos Guarani atuais. Segundo o autor, tal procedimento,

No se trata de buscar simples coincidencias ni de superponer rasgos semejantes, ya que entre los Guaraní actuales y los "históricos" media un largo proceso de interferencias exteriores que ha producido cambios significativos; sino de procurar las categorías fundamentales para una reestructuración semántica que sea auténticamente guaraní. Los conocimientos que se tienen de la cultura guaraní actual, gracias a los trabajos de Nimuendajú, Cadogan y Schaden, permiten apelar a este recurso con seriedad (MELIÀ, 1997, p. 100).

Tal procedimento se depara com algumas críticas, sobretudo entre os teóricos do “desenvolvimento cultural”, para os quais não é possível a suposição de que haja continuidade entre os “modos de vida” dos grupos indígenas pré e pós-conquista (ROOSEVELT, 1989 Apud FAUSTO, 1992, p. 381). A esse respeito, Carlos Fausto concorda que seria ingenuidade desconsiderar as rupturas que a conquista colonial representa para as culturas indígenas. No entanto, conforme este autor, também seria ingenuidade imaginar que existe uma simples correlação entre demografia e complexidade sociocultural ou sociopolítica. Se assim fosse, a dizimação física corresponderia a alteração proporcional e previsível no que diz respeito aos aspectos culturais. Segundo Fausto, ao contrário disso, as crônicas coloniais sobre os Tupi da costa apresentam uma inegável familiaridade com os Tupi atuais (FAUSTO, 1992, p. 381). Essa mesma familiaridade também pode ser observada sob alguns aspectos na relação entre os Guarani atuais e a documentação histórica a seu respeito. É evidente que esse recurso, chamado de projeção etnográfica, precisa ser utilizado com muita cautela, pois existe o forte risco de se retratar os povos indígenas com “eternos”, "fossilizados” ou “estáticos”, ou seja, como povos que não mudaram desde a conquista colonial. A isso equivaleria dizer que são povos sem história, o que é o oposto perfeito à ideia defendida pela atual pesquisa em história indígena. Essa cautela também não pode desconsiderar que cada cultura tem sua própria historicidade, isso, entre outras coisas, significa dizer que o ritmo das mudanças é diferente nas diferentes culturas.

Por outro lado, corre-se o risco de, numa busca cega pela historicidade dos elementos socioculturais e políticos indígenas, voltar-se o olhar apenas para a dimensão das mudanças, deixando esquecida a dimensão das permanências, que também é parte importante da historicidade 
de uma cultura. Nas palavras de Sahlins “[...] As coisas devem preservar alguma identidade através das mudanças ou o mundo seria um hospício[...]” (2003, p. 190).

Com relação ao método interdisciplinar etno-histórico, José Luis de Rojas (2008, p. 118) fez uma observação bastante interessante ao assinalar que "Las disciplinas disciplinan”, assim sendo, a etno-história representa uma porção de liberdade metodológica que propicia ao pesquisador partir de um problema que se quer analisar e é o problema que determina as fontes e o método que se quer utilizar e não o inverso. Isso porque os métodos devem estar a serviço da pesquisa e não o inverso. Por conta própria, acrescenta-se também, que as teorias devem estar a serviço da pesquisa e não o inverso. Evidentemente que isso não equivale a dizer que vale tudo, antes disso, o pesquisador que adere a essa prática metodológica precisa adquirir certo grau de domínio das metodologias e teorias das diferentes áreas envolvidas (ROJAS, 2008).

Nesse sentido o problema da formação de profissionais com visão interdisciplinar é um grande desafio. De fato, a maioria dos pesquisadores que trabalha com o método etno-histórico no Brasil é oriunda ou da antropologia ou da história, havendo também, em menor quantidade, mas com grande importância, a participação de outros profissionais. O fato é que, em geral, as formações oferecidas em nível de graduação no Brasil, e mesmo em nível de pós-graduação, com algumas exceções, são bastante disciplinares. Essa situação não parece ser tão diferente em outras partes do mundo, pois José Luis Rojas destaca que há pouquíssimos lugares no mundo onde se oferecem graduações específicas ou especialidades em etno-história. Assim, quase sempre, os profissionais precisam se dedicar sozinhos para completar a sua formação, constituindo-se, em muitos casos, em verdadeiros autodidatas (ROJAS, 2008).

Acredita-se que um bom encaminhamento para a questão não seja o oferecimento de cursos de graduação em etno-história. A saída mais saudável seria o oferecimento de disciplinas pertinentes às áreas nas diferentes graduações, um núcleo comum de formação humanística nos primeiros anos dos cursos seria uma ótima alternativa. Cursos de etnologia, arqueologia e linguística ainda são muito incomuns nos cursos de história. Da mesma forma, disciplinas sobre método historiográfico são ainda mais raras nos cursos de ciências sociais, nos quais muitos antropólogos recebem sua formação inicial (EREMITES DE OLIVEIRA, 2001).

Esse quadro acaba por gerar situações em que pesquisadores oriundos da antropologia acusam os historiadores de não saberem lidar adequadamente com dados etnográficos e tradições orais; por outro lado, os oriundos da história acusam os antropólogos de utilizar as fontes históricas, principalmente as escritas, de maneira acrítica (CARMACK, 1979; TRIGGER, 1982). Esse tipo de problema, de fato, em muitos casos é verídico. O livro de José Luis Rojas, por exemplo, que é historiador de formação inicial, dá ênfase muito maior para as metodologias ligadas à análise 
documental do que para as outras metodologias envolvidas na questão. Não que ele faça isso de maneira inconsciente, pois no capítulo intitulado "La Documentación”, afirma que “[...] Nos encontramos nuevamente con que cada uno arrima el ascua a su sardina y, en cierta medida, yo voy a hacer lo mismo, aunque con ligera pretensión de presentar un tipo de 'sardina' que pueda ser ampliamente compartido[...]” (ROJAS, 2008, p. 51).

Essa dificuldade será superada mais facilmente quando as universidades brasileiras começarem a ampliar a prática do discurso interdisciplinar, que já está bastante disseminado. Infelizmente o que se vê, em muitos casos, é o império das atitudes disciplinares, chegando, em alguns casos, às vias de algo comparável à xenofobia. A expressão mais ilustrativa disso, além dos currículos dos cursos, é a exigência de formação linear, ou seja, graduação e doutorado na mesma área, como requisito básico para os concursos públicos promovidos para admissão de pesquisadores e docentes. Essa situação desestimula os estudantes a buscarem uma formação mais interdisciplinar, sob pena de terem dificuldades para inserção no mercado de trabalho. É paradoxal que as universidades ofereçam atualmente no Brasil 335 cursos de pós-graduação, entre mestrados, mestrados profissionalizantes e doutorados, vinculados à área de avaliação “multidisciplinar” da Coordenação de Aperfeiçoamento de Pessoal de Nível Superior do Ministério da Educação do Brasil (CAPES, 2010). O Paradoxo é verificado porque, ao menos na área de ciências humanas, raramente os egressos desses programas são contemplados pelos editais de universidades públicas para contratação de docentes e pesquisadores, e o que é mais intrigante, é que isso também acontece em algumas instituições que oferecem, ou pleiteiam autorização para oferecer, cursos dessa natureza.

É evidente que há um leque muito grande de possíveis interações entre as várias disciplinas inseridas no diálogo interdisciplinar aqui tratado. Não há aqui condições de se abordar esse aspecto de maneira muito profunda, mas é evidente que nem toda visão da antropologia, da história, da arqueologia ou de outras disciplinas envolvidas, contribui para a construção de uma história indígena a partir do método etno-histórico. As escolhas cabem a cada pesquisador, que deve buscar as alternativas mais adequadas ao problema proposto.

A título de exemplo, destaca-se que, a já citada, inclusão da arqueologia, ainda pouco trabalhada em uma relação mais holística com a história indígena, contribui sobremaneira para que se possa pensar a história indígena a partir de um ponto de vista mais integral. Assim pode-se ter uma abordagem de longa duração, na qual a história indígena não tem seu início marcado pelo início da conquista e colonização do continente americano, isso pensando no estudo dos povos indígenas da América, mas consciente de que esse método também é aplicado em outras regiões do mundo. 
Muito embora o método etno-histórico tenha sido desenvolvido e aplicado, sobretudo para a compreensão dos aspectos históricos dos grupos não-ocidentais, muitas vezes ágrafos, há também a possibilidade de aplicação no que seria uma perspectiva êmica a partir da visão ocidental. Lilia Moritz Schwartz coordena o Núcleo de Pesquisa de Etno-História do departamento de Antropologia da Universidade de São Paulo, ali, para surpresa de muitos, os objetos de pesquisa não estão relacionados à história indígena, mas à nossa própria sociedade, terreno de uma antropologia histórica, que segundo a autora, pretende, “[...] à semelhança do que a etno-história realiza para outras culturas, recuperar um trabalho de 'tradução para as sociedades complexas'. Esse tipo de antropologia nos levaria a ser capazes de representar nossa própria sociedade e, por que não?, o tempo e a história [...]” (SCHWARTZ, 2005, p. 134).

Levando em consideração que o estudo da humanidade não se restringe aos domínios de nenhuma disciplina. Considerando ainda que os povos indígenas têm culturas, historicidades e modos de se expressar bastante diversos, a etno-história se apresenta como uma metodologia potencialmente favorável para a construção de uma história indígena mais holística. Além disso, como se vê nas proposições de Lilia Schwartz (2005), é possível transpor esse método também para a compreensão das sociedades ocidentais.

\section{História Indígena}

Acredita-se que a história indígena é a melhor designação para o campo de pesquisas que vem sendo tratado neste artigo. Dentro dessa proposta, a etno-história se configura como uma metodologia bastante eficaz de trabalho. Para finalizar, discutir-se-ão agora alguns aspectos deste campo de pesquisas.

Já foi anteriormente citada a perspectiva de negação da possibilidade de uma história indígena amplamente difundida durante o século XIX e por quase todo o século XX no Brasil, mas também de modo geral no mundo ocidental. Como afirmou Manuela Carneiro da Cunha (1992), durante muito tempo os indígenas não foram vítimas apenas da eliminação física, mas também da eliminação enquanto sujeitos históricos.

A década de 1990 marcou um momento de guinada, pois várias novas iniciativas frutos da articulação entre antropólogos, arqueólogos e historiadores trouxeram à tona trabalhos com perspectivas renovadas. Pode-se destacar a publicação da coletânea “História dos Índios no Brasil” (CUNHA, 1992) como um marco importante para a história indígena no país. Além desse, há vários outros trabalhos que se tornaram marco de referência da historiografia sobre o assunto, como, por exemplo, “Negros da Terra” de John Manuel Monteiro (1994) e "Ensaios em Antropologia 
Histórica” de João Pacheco de Oliveira (1999). Nesse período também se viu florescer a formação de vários especialistas na área, que, embora ainda não sejam tão numerosos, têm contribuído para com o avanço das pesquisas e para a formação de novos pesquisadores. Observa-se também a interiorização e a ampliação do número de instituições que começam a abrir espaço para esse tipo de pesquisa.

No presente momento observa-se um franco crescimento, não só numérico, mas, sobretudo em termos qualitativos da produção científica da área. Percebe-se também que aos poucos os historiadores e arqueólogos adquirem maior participação na produção da área, que foi inicialmente levantada e defendida por uma maioria de antropólogos. Os sinais disso são vários, como, por exemplo, a inserção de simpósios temáticos sobre história indígena em todas as edições a partir de 2003 do Simpósio Nacional de História, o maior evento bianual de história realizado no Brasil sob organização da Associação Nacional de História. Também é possível destacar a publicação de dossiês temáticos em várias revistas científicas do país, como, por exemplo, "Revista de Antropologia” (1989), “Revista Eletrônica História em Reflexão” (2007), “Revista Fronteiras” (1998), “Revista de História” (2006) e “Tempo” (2007).

Mas não se pode enganar, apesar de tudo o que já foi feito, há um longo caminho a ser percorrido. Em 2008 a Lei Federal no 11.645, a exemplo do que já era previsto desde 2003 em relação à história e cultura afro-brasileira, tornou obrigatório o estudo da história e cultura indígena nos estabelecimentos de ensino fundamental e médio do país. Como já foi destacado em outro trabalho (CAVALCANTE, 2008), a legislação traz otimismo, mas também certa melancolia por saber que é necessária uma obrigação legal para oferecer algum espaço à história indígena ou ao indígena na história do Brasil ensinada nas escolas. Apesar dessa questão, esse dispositivo legal pode contribuir para o desenvolvimento da pesquisa em história indígena, pois se espera que as instituições de ensino superior abram novos postos de trabalho nessa área. Isso propiciará a contratação de professores e pesquisadores comprometidos com a temática e a formação de licenciados habilitados para o ensino da questão nas escolas.

Para o sucesso efetivo dessa legislação, é fundamental que seja superada a perspectiva eurocêntrica e evolucionista presente em muitos currículos escolares. Observa-se que em muitos casos, tanto a história e a cultura da África ou afro-brasileira, quanto a história e a cultura dos indígenas são inseridas nas atividades escolares por meio de projetos anexos, mas desconectados das atividades curriculares normais. Essa forma de cumprimento da obrigação legal tem caráter apenas burocrático e pode ter um efeito inverso ao esperado, pois tratar dessas histórias de forma isolada da dita história nacional pode reforçar preconceitos, visto que são apresentadas somente na “semana do índio” e na "semana da consciência negra” de forma desconexa em relação à chamada 
“História do Brasil”. Nos livros didáticos em geral, os indígenas figuram apenas nos capítulos que tratam da "pré-história” e do período da conquista do continente, contribuindo assim para a consolidação de uma visão fossilizada dos povos indígenas e para seu silenciamento nos demais períodos da história nacional.

Um dos principais objetivos desta lei é o de combater os preconceitos em relação aos povos indígenas. Por isso cabe uma reflexão acerca de qual história indígena será ou está sendo ensinada? Esta é uma importante questão, uma questão que foge ao controle legal, o que amplia a responsabilidade do meio acadêmico sobre essa reflexão. O papel da academia é importantíssimo, pois ela tem se configurado como o espaço privilegiado de produção de conhecimento, conhecimento esse que tende a ser didatizado. Portanto, a história ensinada é, de certo modo, reflexo da produção acadêmica universitária (sem, é claro, aprofundar em discussões sobre a ideologização da construção de currículos e materiais didáticos). Além disso, a formação de licenciados sensíveis à questão é urgente.

Nesse sentido alguns pontos podem ser destacados. Primeiramente, é importante caminhar no sentido, já defendido anteriormente, de uma história indígena que não seja temporalmente determinada pela história colonial. Ou seja, a historiografia não pode repetir a ideia de que a história indígena começa com a dominação colonial, pois é sabido que há muita história na chamada "préhistória”. Uma abordagem nesse sentido só avançará com a inclusão mais sistemática da arqueologia nas pautas de discussão sobre história indígena (CARNEIRO DA CUNHA, 1992; EREMITES DE OLIVEIRA, 2001).

É preciso, também, promover a descolonização do discurso histórico, isso é possível a partir do momento em que os povos indígenas sejam tomados como sujeitos históricos plenos. Assim sendo, não devem ser tratados apenas como vítimas de processo colonial, mas também como responsáveis pela própria história (CARNEIRO DE CUNHA, 1992, EREMITES DE OLIVEIRA, 2001, PACHECO DE OLIVEIRA, 1999). Isso não significa, de forma alguma, atribuir a culpa de suas mazelas aos próprios indígenas. Jamais se deve esquecer ou omitir que a relação colonial entre indígenas e não-indígenas foi e continua sendo uma relação desigual. Nesse sentido, por exemplo, a própria linguagem utilizada para representar esse momento tem algo de colonial.

Manuela Carneiro da Cunha destaca, por exemplo, que o termo “encontro” não passa de um eufemismo envergonhado (1992, p. 12). Mais do que na perspectiva do "encontro” a questão deve, numa linguagem descolonizada, ser tematizada como “conquista”. Mas isso também não significa esquecer o papel dos atores indígenas que nesses processos estabeleceram diversas formas de intercâmbio com os colonizadores, sendo por vezes aliados do sistema colonial e contribuindo para com ele. 
É sempre bom lembrar que o termo “índio" do qual deriva “indígena” é um termo generalizante que não reflete a diversidade de povos e culturas existentes na América. Seu uso é aceito apenas no sentido de oposição entre povos de origem européia, de culturas ocidentais e os “nativos” de culturas não-ocidentais, mas nunca se deve imaginar que os povos indígenas tenham em algum momento constituído um bloco monolítico. São, portanto, importantes as relações de aliança e conflito historicamente observadas entre povos diversos e mesmo as relações políticas e sociais internas a cada grupo.

Pode-se abordar a questão no sentido de uma "história indígena”, mas também no sentido de uma "história da presença indígena na história do Brasil (ou outros países, ou na América etc.)”. Ambas são abordagens possíveis e importantes. A história indígena, enquanto tal pode ser pensada como a história específica de cada grupo, ou de movimentos indígenas, por exemplo. Enfim, nessa abordagem a perspectiva do olhar está sobre a história particular e pode ser pensada da mesma maneira como se pensa em uma "história do Brasil”, ou "história da América”, etc. Mas a história indígena não pode ignorar os processos coloniais nos quais os povos estão inseridos (PACHECO DE OLIVEIRA, 1998).

Não se pode imaginar que um grupo tenha continuado sua história livre da interferência colonial. Nesse sentido, Carneiro da Cunha destaca que a própria noção de isolamento precisa ser relativizada, pois se sabe que os contatos indiretos, por meio de artefatos e microrganismos, foram muito mais rápidos do que os diretos (CUNHA, 1992). Apesar de sempre levar em conta o contexto colonial, a abordagem da história indígena parte do princípio epistemológico de que os povos indígenas têm história e que sua história é digna de ser estudada independente do grau de relação que ela tenha com o contexto colonial, ou seja, a história colonial só precisa ser abordada até o ponto em que afeta a história indígena (TRIGGER, 1982).

A abordagem da presença indígena na história do Brasil é igualmente importante, mais alinhada com a proposta já exposta de Rojas (2008), tende a se debruçar sobre a participação dos indígenas nos temas mais abrangentes da história nacional, ressaltando a importância dos papéis desempenhados por esses povos. Essa proposta está ligada ao urgente fim do silenciamento visto em muitas páginas da historiografia nacional, nas quais a participação indígena é sistematicamente ocultada ou inferiorizada. Nessa linha de intersecção pode-se colocar, também, a história do indigenismo, que se preocupa, sobretudo, com a relação entre os povos indígenas e o Estado, mas também com outros agentes, como organizações não-governamentais e missões religiosas. A história da política indígena também não deve ser esquecida, pois não se pode pensar em uma história da política indigenista desconectada da história da política indígena (CUNHA, 1992). 
Para todas essas abordagens o método etno-histórico oferece ferramentas eficazes para o manejo de diferentes categorias de fontes. Não obstante, cabe destacar que as fontes de origem indígena (orais, materiais, visuais, escritas ou audiovisuais) têm muita importância para uma abordagem que vise devolver ao indígena o papel de protagonista de sua história. Não se deve esquecer, é claro, da supracitada crítica de Gruzinski, no sentido de que a ênfase extrema no protagonismo indígena e o recurso exclusivo às fontes indígenas podem ocultar a relação colonial, o que não seria positivo para a compreensão da história indígena pós-conquista (GRUZINSKI, 2007).

A história indígena deve representar os povos indígenas como povos históricos, ou seja, não pode reproduzir o discurso do “índio eterno” estereotipado e exótico, no entanto, nem sempre é isso o que se vê. É obvio que em graus diferenciados todos os povos indígenas sofreram mudanças culturais em razão da relação colonial instaurada na América desde o final do século XV. Sabendo disso, é, todavia, preciso ressaltar que as culturas indígenas, assim como as não-indígenas, respeitando suas diferentes historicidades, não teriam permanecido estáticas se a conquista e colonização não tivessem ocorrido. Fazer essa ressalva não é o mesmo que dizer que as culturas indígenas estariam, como atualmente se encontram se não tivessem sido partes do processo colonial, mas sim, é reafirmar sua historicidade.

Não é raro ouvir ou ler pesquisadores das questões indígenas afirmando que os povos indígenas “perderam” ou “estão perdendo” a sua cultura, ou ainda, que é preciso "resgatar” essa cultura. Esse pensamento favorece a construção de uma história indígena que parece mais uma história do desaparecimento dos povos indígenas. Trata-se, na opinião deste pesquisador, de uma visão distorcida, pois a cultura não é algo que se perde, mas algo que se transforma. Esse processo de transformação pode evidentemente ser tematizado, mas com uma abordagem diferente dessa que está sendo criticada (Esta crítica não é dirigida às iniciativas êmicas de preservação cultural, que têm outra natureza). Pensando assim, conclui-se que alguns elementos ocidentais são incorporados à cultura indígena.

A ideia de “indigenização” (SAHLINS, 1997) é bastante interessante nesse sentido, pois a partir dela se pode entender que elementos não-indígenas são indigenizados, passando, portanto, a compor a cultura indígena, da mesma forma que muitos elementos indígenas foram ocidentalizados. A partir daí, é possível pensar, por exemplo, o fenômeno das diversas igrejas indígenas cristãs que existem em Mato Grosso do Sul. Mostrar que o indígena de hoje não é, e, sobretudo, não tem a obrigação de ser como seus antepassados do século XV é fundamentalmente importante, principalmente no que diz respeito aos direitos indígenas.

Ainda é frequente a confusão entre os conceitos de “cultura” e "etnia” quando se buscam critérios de indianidade. Ao tratar esses dois conceitos como sinônimos, propaga-se a ideia de que o 
indígena para ser indígena precisa ter um grande bojo de sinais diacríticos que marquem sua diferença em relação à sociedade envolvente. Trata-se de uma perspectiva tola, pois aqueles ocidentais, que quase não se parecem mais com seus avôs, exigem que os indígenas sejam como seus ancestrais pré-coloniais, negando-lhes novamente a sua historicidade. É evidente que aí há um discurso político implícito, discurso esse que visa afirmar que os indígenas que usam roupas ocidentais, televisão, telefones celulares, computadores, etc., não são mais indígenas, consequentemente não têm mais os direitos constitucionais que lhes são garantidos. A história indígena precisa ajudar a desconstruir esse discurso, demonstrando que as culturas são históricas e ressaltando que os critérios de identificação étnica estão muito mais relacionados às relações sociais do que a culturais (BARTH, 2000).

O último ponto a ser abordado neste artigo diz respeito ao compromisso ético-profissional que é reforçado diante da relevância social que a pesquisa em história indígena adquiriu no Brasil. Semelhante ao que já foi relatado em relação ao surgimento da etno-história nos Estudos Unidos, no Brasil a história indígena começou a ganhar força justamente no momento em que a nova Constituição Federal de 1988 garantiu uma série de direitos aos povos indígenas, com grande destaque para o direito a terra.

Segundo o artigo 231 da nova Constituição, os indígenas têm garantidos os direitos originários sobre as terras que tradicionalmente ocupam, cabendo à União demarcá-las e protegêlas. Os estudos históricos, sejam eles produzidos pela academia ou durante as pesquisas realizadas pelos grupos técnicos do órgão indigenista oficial, são elementos muito importantes nesse processo, pois fundamentam os técnicos do governo na elaboração dos relatórios de identificação de terras indígenas. Esses estudos são também frequentemente utilizados durante a realização de perícias solicitadas pelo poder judiciário em causas envolvendo direitos individuais e/ou coletivos de indígenas. Conclui-se, por tanto, que a história indígena tem papel ativo como subsidiadora e legitimadora das ações estatais de garantias ou privações de direitos indígenas.

Diante disso, como destacou Trigger (1982), o pesquisador da história indígena, ainda que seja simpático à causa indígena, e de fato, quase sempre é, não pode jamais abrir mão dos critérios de validação do conhecimento histórico. Com relação a isso, ainda que haja vozes discordantes, é sempre bom lembrar que não há conhecimento histórico sem fontes, entende-se evidentemente que as fontes históricas compreendem um conjunto de vestígios sobre os atos humanos muito mais amplo do que apenas o dos documentos escritos e que para a história indígena o recurso às tradições orais e à cultura material, não é apenas salutar, mas fundamental. O pesquisador precisa ter um compromisso ético diante da consciência da importância de seu trabalho para as reivindicações indígenas. Assim, não há absolutamente necessidade alguma de se produzir trabalhos cuja validade 
acadêmica possa ser questionada, pois o que há, de fato, sobre a história indígena, sendo bem abordado é mais do que suficiente para fundamentar as legítimas reivindicações dos povos indígenas.

Em um artigo como esse é impossível abordar a problemática da história indígena de maneira exaustiva, mas espera-se que o texto tenha contribuído para o aclaramento de alguns conceitos importantes, bem como no estímulo à reflexão sobre alguns dos pontos considerados chave no desafio que é a história indígena.

\section{Agradecimentos}

Agradeço aos professores Paulo Santilli, Jorge Eremites de Oliveira e Protásio Paulo Langer pela leitura e comentários à primeira versão deste artigo. A responsabilidade pelo texto é, no entanto, exclusivamente minha.

\section{Notas}

\footnotetext{
${ }^{1}$ Lei de reivindicações indígenas.

$2<$ http://www.dukeupress.edu/Catalog/ViewProduct.php?productid=45610> - O acesso integral aos textos é livre se for feito a partir de computadores interligados a servidores com acesso livre ao projeto de Periódicos da CAPES $<$ http://novo.periodicos.capes.gov.br/>.

${ }^{3}$ http://www.gbl.indiana.edu/archives/menu.html
}

\section{Referências}

ASE - The American Society for Ethnohistory.<http://www.ethnohistory.org/>, acessado em: 16.06.2010.

ALMEIDA, M. C. História dos Índios na América: abordagens interdisciplinares e comparativas. Entrevista com Serge Gruzinski. Tempo, Niterói, v. 12, n. 23, 2007.

BARTH, F. Os Grupos étnicos e suas Fronteiras. In. O Guru, o iniciador e outras variações antropológicas. Trad. John Cunha Comerford. Rio de Janeiro: Contra Capa Livraria, 2000.

CAPES - Cursos recomendados pela Coordenação de Aperfeiçoamento de Pessoal de Nível Superior. <http://www.capes.gov.br/cursos-recomendados>, acessado em: 16.06.2010.

CASTRO, E. V.; CUNHA, M. C. (Orgs.) Amazônia Etnologia e História Indígena. São Paulo: NHII/USP: FAPESP, 1993.

CAMACK, R. M. Ethnohistoria y teoría antropológica. Trad. F. J. Lima. (Cuadernos, 26). Guatemala: Ministerio de Educación, 1979. 
CAVALCANTE, T. L. V. A obrigatoriedade do ensino da história e cultura indígena nas escolas brasileiras. Douradosnews, Dourados, 13 abr. 2008.

CHAMORRO, G. D. C. Historia y etnografía del cuerpo en los pueblos Guaraní. Asunción: Tiempo de Historia: Fondec, 2009.

CUNHA, M. C. Por um história indígena e do indigenismo. In. . Cultura com Aspas.

São Paulo: Cosac Naify, 2009, p.125-131.

CUNHA, M. C. (Orgs). História dos Índios no Brasil. São Paulo: Companhia da Letras, 1992.

EREMITES DE OLIVEIRA, J. A História Indígena em Mato Grosso do Sul: dilemas e perspectivas. Territórios e Fronteiras, Cuiabá, 2001, v. 2, n. 2, p.115-124.

Sobre os conceitos e as relações entre história indígena e etnoistória. Prosa

Uniderpjun. 2003. v. 3, n. 1, p. 39-48.

FAUSTO, C. Fragmentos de história e cultura tupinambá: da etnologia como instrumento crítico de conhecimento etno-histórico. In. CUNHA, M. C. da (Org). História dos Índios no Brasil. São Paulo: Companhia da Letras, 1992. p. 381-396.

FRONTEIRAS REVISTA DE HISTÓRIA, Campo Grande, UFMS, n. 4, v. 2, pp. 171-201, 1998.

GALDAMES, O. S Etnohistoria o historia indigena? Encuentro de Etnohistoriadores. Santiago: Universidad de Chile, 1988.

MELIÀ, B. El Guaraní Conquistado y Reducido. Ensaios de Etnohistoria. $4^{\mathrm{a}}$ Ed. Asunción: CADUC: CEPAG, 1997.

MONTEIRO, J. M. O desafio da História indígena no Brasil. In. GRUPIONI, Luiz Donizete Benzi; SILVA, Aracy Lopes da Silva. A temática indígena na escola: novos subsídios para professores de 1 e 2 graus. Brasília: MEC:MARI:UNESCO, 1995.

Companhia das Letras, 1994.

. Negros da terra: índios e bandeirantes nas origens de São Paulo. São Paulo:

REVISTA DE ANTROPOLOGIA, São Paulo, USP, n. 30/31/32, 1987/1988/1989.

REVISTA ELETRÔNICA HISTÓRIA EM REFLEXÃO, Dourados, UFGD, v.1, n.2, jun/jul, 2007.

REVISTA DE HISTÓRIA, São Paulo, USP, 2006. nº154.

PACHECO DE OLIVEIRA, J. P.. Ensaios em Antropologia Histórica. Rio de Janeiro: Editora UFRJ, 1999.

Uma etnologia dos “índios misturados”? Situação colonial, territorialização e fluxo culturais. Mana, Rio de Janeiro, UFRJ, v.4, n.1, 1998.

ROJAS. J. L. La Etnohistoria de América. Los indígenas, protagonistas de su historia. Buenos Aires: SB, 2008.

SAHLINS, M. Ilhas de História. Rio de Janeiro: Zahar, 2003. 
. O “pessimismo sentimental” e a experiência etnográfica: por que a cultura não é um “objeto” em via de extinção (parte II). Mana, Rio de Janeiro, UFRJ, 1997, v.3, n.2, p.103150 ,

SCHWARCZ, L. K. M. Questões de Fronteira. Sobre uma antropologia da história. Novos Estudos, julho de 2005, n. 72, p. 119-135,

TEMPO, Niterói, UFF, v.12, n.23, 2007.

TRIGGER, B. G. Etnohistoria: problemas e perspectivas. Traduciones y Comentários. Trad. C. T. Michieli. San Juan, 1982, v. 1, p. 27-55.

.Ethnohistory: problems and prospects. Ethnohistory.1982, v.29, n.1, , p. 1-19.

Recebido em: 09/09/2010

Aprovado em: 09/05/2011 